Check for updates

Cite this: RSC Adv., 2019, 9, 27710

Received 31st May 2019

Accepted 13th August 2019

DOI: $10.1039 / c 9 r a 04135 d$

rsc.li/rsc-advances

\section{Efficient electrocatalytic reduction of carbon dioxide by metal-doped $\beta_{12}$-borophene monolayers $\uparrow$}

\begin{abstract}
Jin-Hang Liu, ${ }^{a}$ Li-Ming Yang (D) *a and Eric Ganz (D) ${ }^{\text {b }}$
Electrochemical reduction of $\mathrm{CO}_{2}$ to value-added chemicals and fuels shows great promise in contributing to reducing the energy crisis and environment problems. This progress has been slowed by a lack of stable, efficient and selective catalysts. In this paper, density functional theory (DFT) was used to study the catalytic performance of the first transition metal series anchored $T M-B_{\beta 12}$ monolayers as catalysts for electrochemical reduction of $\mathrm{CO}_{2}$. The results show that the $\mathrm{TM}-\mathrm{B}_{\beta 12}$ monolayer structure has excellent catalytic stability and electrocatalytic selectivity. The primary reduction product of $\mathrm{Sc}-\mathrm{B}_{\beta 12}$ is $\mathrm{CO}$ and the overpotential is $0.45 \mathrm{~V}$. The primary reduction product of the remaining metals $(\mathrm{Ti}-\mathrm{Zn})$ is $\mathrm{CH}_{4}$, where $\mathrm{Fe}-\mathrm{B}_{\beta 12}$ has the minimum overpotential of $0.45 \mathrm{~V}$. Therefore, these new catalytic materials are exciting. Furthermore, the underlying reaction mechanisms of $\mathrm{CO}_{2}$ reduction via the $\mathrm{TM}-\mathrm{B}_{\beta 12}$ monolayers have been revealed. This work will shed insights on both experimental and theoretical studies of electroreduction of $\mathrm{CO}_{2}$.
\end{abstract}

\section{Introduction}

With the development of society and the economy, the energy crisis and the greenhouse effect have received more and more attention because of the serious impact on the environment. ${ }^{1}$ The conversion of $\mathrm{CO}_{2}$ into fuels and various chemicals would not only effectively alleviate the dependence on fossil fuels, but also potentially reduce the harm caused by the greenhouse effect. $^{2-6}$ Carbon dioxide as a non-polar molecule is often considered an inert material with a unique linear structure. This determines the chemical reaction of $\mathrm{CO}_{2}$ under special conditions (such as high temperature, high pressure with a catalyst). Based on factors such as energy requirements, process speed, and cost, electrochemistry is a promising method for these reactions due to its advantages such as mild reaction conditions. ${ }^{7-12}$

Due to their high specific surface area, reduced dimensionality and exotic properties, two-dimensional (2D) nanosheets have become an ideal platform for the design of novel electrocatalysts for $\mathrm{CO}_{2}$ reduction. ${ }^{\mathbf{1 3 - 1 6}}$ Borophene is a novel 2D

${ }^{a}$ Hubei Key Laboratory of Bioinorganic Chemistry and Materia Medica, Key Laboratory of Material Chemistry for Energy Conversion and Storage, Ministry of Education, Hubei Key Laboratory of Materials Chemistry and Service Failure, School of Chemistry and Chemical Engineering, Huazhong University of Science and Technology, Wuhan 430074, China. E-mail: Lmyang.uio@gmail.com; Lmyang@hust. edu.cn

${ }^{b}$ School of Physics and Astronomy, University of Minnesota, 116 Church St. SE, Minneapolis, Minnesota 55455, USA

$\dagger$ Electronic supplementary information (ESI) available. See DOI: 10.1039/c9ra04135d material under active investigation with fascinating and diverse properties and potential. ${ }^{17}$ Recently, honeycomb borophene has been experimentally fabricated on an $\mathrm{Al}(111)$ substrate. ${ }^{18}$ This experimental work then triggered the theoretical discovery of a new $2 \mathrm{D}$ anti-van't Hoff/Le Bel ptAl array $\mathrm{AlB}_{6}$ which is predicted to have rare triple Dirac cone electronic structure as well as superconductivity. ${ }^{19}$ This is an example of how the properties of borophene can be enhanced and extended by alloying with other elements. This may provide new opportunities to design functional materials or catalysts.

To the best of our knowledge, the application of TM- $\mathrm{B}_{\beta 12}$ monolayers as new single-atom catalysts for electrocatalytic $\mathrm{CO}_{2}$ reduction reaction (CRR) has not been achieved. Therefore, we performed a systematic study on the catalytic performance of $\mathrm{TM}-\mathrm{B}_{\beta 12}(\mathrm{TM}=\mathrm{Sc}-\mathrm{Zn})$ monolayers for CRR using density functional theory (DFT). The results show that for the 10 materials studied, all have good stability and CRR selectivity. For Sc, the primary reduction product is $\mathrm{CO}$. For the other materials, the primary product is $\mathrm{CH}_{4}$, with the overpotential as low as $0.45 \mathrm{~V}$. We predict that these monolayers will be promising CRR catalysts.

\section{Computational methods}

Structural optimization, total energy and electronic properties (density of states, charge analysis) were calculated using spin polarized density functional theory. All of the calculations were carried out using the $\mathrm{DMol}^{3}$ module of Materials Studio 2016. ${ }^{20}$ Exchange correlation used the generalized gradient 
approximation (GGA). ${ }^{21}$ Exchange correlation functions used Perdew, Burke and Ernzerhof (PBE), and basis sets used double numerical polarization (DNP) basis sets and all-electronic methods to process the electrons in the system..$^{22}$ In order to better describe the adsorption of molecules on the catalyst surface, the van der Waals Correction (DFT-D2) was added to the calculation. ${ }^{23}$ Since electrochemical catalysis is carried out in aqueous solution, the conductor-like screening model (COSMO) was used as the solvation model for better agreement with the experiment, and the dielectric constant of water $(\varepsilon)$ is set to $78.54 .^{24}$ In order to eliminate the interactions between adjacent images, the vacuum layer thickness was selected to be $15 \AA$. In order to improve the accuracy of the calculations, the energy convergence criterion was $10^{-6} \mathrm{eV}$, and smearing of $0.005 \mathrm{Ha}$ was added to accelerate the energy convergence. In structural optimization and electronic structure calculations, Monkhorst-Pack $k$-point grids of $5 \times 5 \times 1$ and $12 \times 12 \times 1$ were used respectively.

The adsorption energy is a measure of the interaction between intermediates and the $\mathrm{TM}-\mathrm{B}_{\beta}$ monolayer. Formula (1) defines the adsorption energy (for example, for $\mathrm{CH}_{4}$ ):

$$
E_{\mathrm{ads}}=E_{\mathrm{TM}-\mathrm{B}_{\beta 12}-\mathrm{CH}_{4}}-\mathrm{E}_{\mathrm{TM}-\mathrm{B}_{\beta 12}}-E_{\mathrm{CH}_{4}}
$$

where $E_{\mathrm{TM}-\mathrm{B}_{\beta 12}-\mathrm{CH}_{4}}, E_{\mathrm{TM}-\mathrm{B}_{\beta 12}}$ and $E_{\mathrm{CH}_{4}}$ represent the total energy of $\mathrm{CH}_{4}$ adsorbed on the TM- $\mathrm{B}_{\beta 12}$ surface, the energy of the TM$\mathrm{B}_{\beta 12}$ monolayer, and the energy of a single $\mathrm{CH}_{4}$ molecule, respectively. The concept of Gibbs free energy is introduced in order to determine the optimal reaction paths of CRR. Formula (2) defines the Gibbs free energy:

$$
\Delta G=\Delta E+\Delta E_{\mathrm{ZPE}}-T \Delta S+\Delta G_{\mathrm{pH}}+\Delta G_{\mathrm{U}}
$$

The electrocatalytic reduction of $\mathrm{CO}_{2}$ involves electron transfer, so the energy of this reaction can be calculated by the reference standard hydrogen electrode method proposed by Nørskov and co-workers. ${ }^{25}$ In the formula $\Delta E$ is the reaction energy of each protonation step, $\Delta E_{\mathrm{ZPE}}$ and $\Delta S$ are the change of zero point energy and entropy value, and $T$ is the thermodynamic temperature of the reaction $(298.15 \mathrm{~K}) . \Delta G_{\mathrm{pH}}$ is due to the effect of different $\mathrm{pH}$ values of the solution on the Gibbs free energy of reaction $\left(\Delta G_{\mathrm{pH}}=2.303 k_{\mathrm{B}} T \mathrm{pH}\right)$. The $\mathrm{pH}$ value in acidic solution is assumed to be $0 . \Delta G_{\mathrm{U}}$ is due to the influence of different electrode potentials on the free energy of reaction. $\Delta G_{\mathrm{U}}$ can be produced by the formula

$$
\Delta G_{\mathrm{U}}=-n e U
$$

In this formula, $n$ is the number of transfer electrons, and $e$ is the electron charge, and $U$ is the electrode potential. The catalytic performance of the $\mathrm{TM}-\mathrm{B}_{\beta 12}$ monolayers can be evaluated using the limit potential $\left(U_{\mathrm{L}}\right)$ and the overpotential $(\eta)$. The limit potential is calculated by the formula

$$
U_{\mathrm{L}}=-\Delta G_{\max } / n e
$$

where $\Delta G_{\max }$ is the change of free energy of the decisive step. The overpotential is calculated by the difference between the equilibrium potential and the limit potential. The formula is

$$
\eta=U_{\text {equilibrium }}-U_{\mathrm{L}}
$$

The higher the overpotential, the more difficult the reaction. Therefore, a good CRR catalyst must have a small overpotential.

\section{Results and discussion}

\subsection{Structural features of the $\mathrm{TM}-\mathrm{B}_{\boldsymbol{\beta} 12}$ monolayer}

Fig. 1 shows top and side views of the $\mathrm{TM}-\mathrm{B}_{\beta 12}$ monolayers in the $3 \times 3$ computational supercell. In this paper, we studied

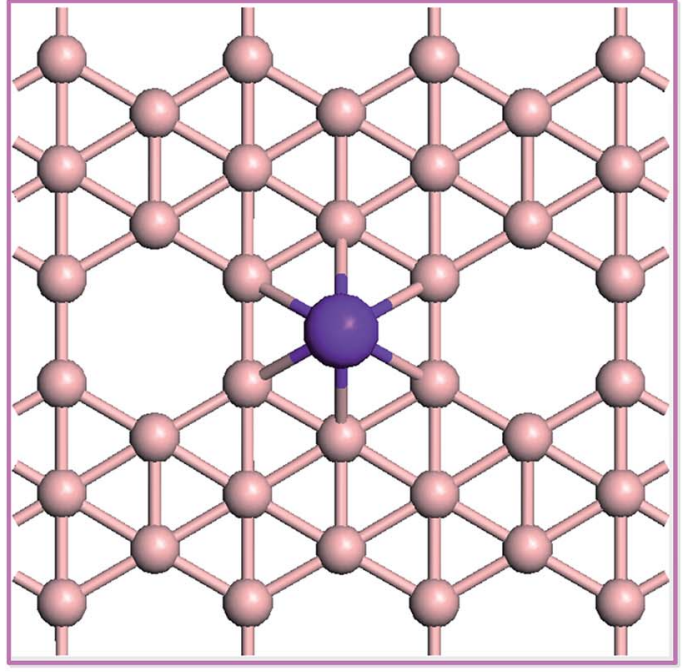

(a)

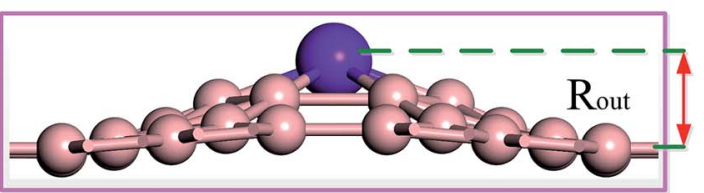

(b)

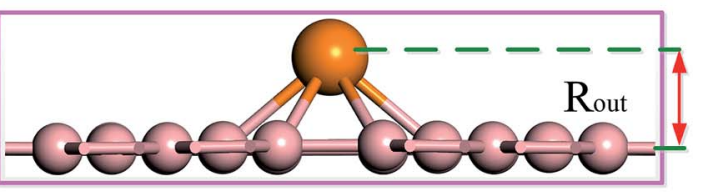

(c)

Fig. 1 Optimized geometric structure of the TM- $B_{\beta 12}$ monolayers in the $3 \times 3$ computational supercell. (a) Top view, (b) and (c) side views. The pastel pink, orange and purple balls represent $\mathrm{B}, \mathrm{TM}(\mathrm{TM}=\mathrm{Sc}, \mathrm{Cu}$ and $\mathrm{Zn})$ and $\mathrm{TM}(\mathrm{TM}=\mathrm{Ti}-\mathrm{Ni})$, respectively. $R_{\text {out }}$ is the distance between the metal atom and the plane of the $B_{\beta 12}$ sheet. 
Table 1 Calculated Hirshfeld charge on the metal atoms $\left(Q_{T M}\right)$, and the boron atoms $\left(Q_{B}\right)$, Hirshfeld spin of the metal atoms (spin-TM), the height of the metal atom protruding from the surface of the monolayer $\left(R_{\text {out }}\right)$, and the TM-B bond length $\left(R_{\mathrm{TM}-\mathrm{B}}\right)$ of the metal atoms with the boron atoms

\begin{tabular}{lcllll}
\hline $\mathrm{TM}-\mathrm{B}_{\beta 12}$ & $Q_{\mathrm{TM}} / \mathrm{e}$ & Spin-TM & $Q_{\mathrm{B}} / \mathrm{e}$ & $R_{\text {out }} / \AA$ & $R_{\mathrm{TM}-\mathrm{B}} / \AA$ \\
\hline $\mathrm{Sc}$ & 0.933 & 0.000 & -0.081 & 1.748 & 2.399 \\
$\mathrm{Ti}$ & 0.676 & 0.000 & -0.069 & 1.818 & 2.138 \\
$\mathrm{~V}$ & 0.485 & 0.000 & -0.048 & 1.717 & 2.022 \\
$\mathrm{Cr}$ & 0.465 & 0.000 & -0.059 & 1.564 & 1.949 \\
$\mathrm{Mn}$ & 0.138 & 3.910 & -0.013 & 1.487 & 1.917 \\
$\mathrm{Fe}$ & 0.047 & 2.743 & -0.002 & 1.370 & 1.897 \\
$\mathrm{Co}$ & 0.059 & 1.801 & -0.005 & 1.353 & 1.895 \\
$\mathrm{Ni}$ & 0.038 & 0.000 & -0.004 & 1.461 & 1.934 \\
$\mathrm{Cu}$ & 0.422 & 0.000 & -0.061 & 1.424 & 2.214 \\
$\mathrm{Zn}$ & 0.521 & 0.000 & -0.057 & 1.541 & 2.262 \\
& & & & &
\end{tabular}

the 10 metals of the first transition metal series. The results show that all 10 metal atoms protrude from the surface of the monolayer (as shown in Fig. $1 \mathrm{~b}$ and c). This may be due to the fact that the B-B bond lengths are quite small, so that the space in the six-membered ring is limited, and so the TM atoms must protrude from the plane. It can be seen from Table 1 that the bond lengths of the metal atoms with the boron atoms $\left(R_{\mathrm{TM}-\mathrm{B}}\right)$ are in the range of 2.399 to $1.895 \AA$, and from $\mathrm{Sc}$ to $\mathrm{Zn}$ the overall trend is decreasing. In addition, the height of the metal atoms up from the surface of the boron monolayer $\left(R_{\text {out }}\right)$ is also decreasing from 1.818 to $1.353 \AA$. In order to study the charge transfer in these materials, Hirshfeld charge analysis was carried out. ${ }^{26}$ From the data in Table 1 , all metal atoms have a partial positive charge, while the adjacent six B atoms have a partial negative charge. This shows that the metal atoms transfer electrons to the B atoms, which causes the metal atoms to have partial ionic bonds with their neighbors. In addition, the calculation results show that except for $\mathrm{Mn}, \mathrm{Fe}$, and Co the remaining seven

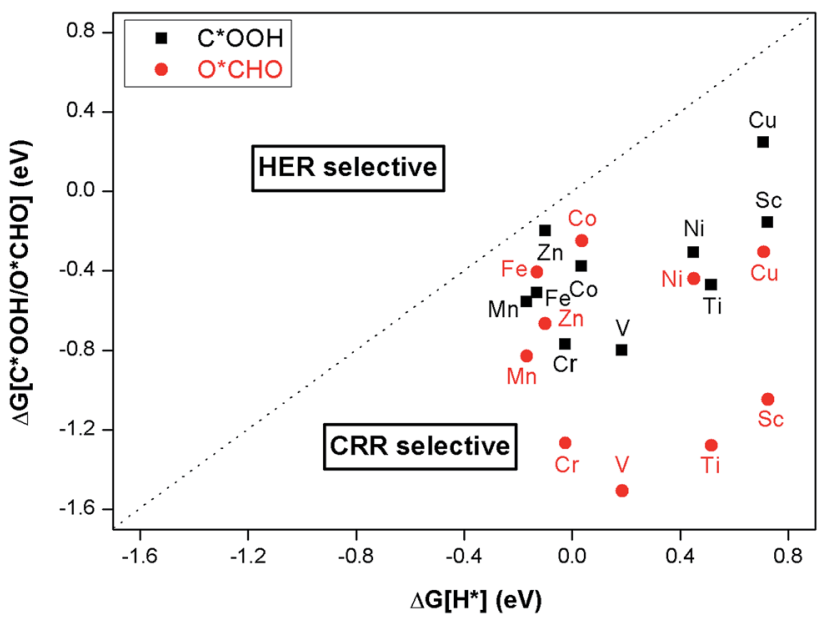

Fig. $3 \Delta G_{\mathrm{COOH}^{*}}$ and $\Delta G_{\mathrm{OCHO}}$ are the Gibbs free energy change of the first protonation step in CRR and $\Delta G_{H^{*}}$ is for HER. Catalysts below the dotted line are CRR selective.

metals have zero spin. The maximum magnetic moment is for Mn with $3.91 \mu_{\mathrm{B}}$.

\subsection{Stability of single $\mathrm{TM}$ atoms embedded in $\mathrm{B}_{\beta 12}$}

For the catalyst to be durable in practical applications, its structure must have excellent stability. Therefore, to evaluate the stability and viability of these monolayers as potential electrocatalysts for $\mathrm{CO}_{2}$ reduction, we calculated the binding energies of single atoms, three and four dispersed atoms, and clusters (composed of three and four metal atoms) onto the $\mathrm{B}_{\beta 12}$ monolayer. We also calculated the cohesive energy of the bulk metals. For ease of discussion, we label the relevant energy values as $E_{\mathrm{b}}^{\mathrm{SAC} 1}, E_{\mathrm{b}}^{\mathrm{SAC} 3}, E_{\mathrm{b}}^{\mathrm{SAC} 4}, E_{\mathrm{b}}^{\mathrm{CL} 3}, E_{\mathrm{b}}^{\mathrm{CL} 4}$ and $E_{\mathrm{c}}$. The detailed results are shown in Table S1. $\dagger$ A typical example comparing $E_{\mathrm{b}}^{\mathrm{SAC} 3} v s . E_{\mathrm{b}}^{\mathrm{CL} 3}$ and $E_{\mathrm{b}}^{\mathrm{SAC} 4}$ vs. $E_{\mathrm{b}}^{\mathrm{CL} 4}$ for $\mathrm{Fe}-\mathrm{B}_{\beta 12}$ can be found in Fig. S2. $\dagger$
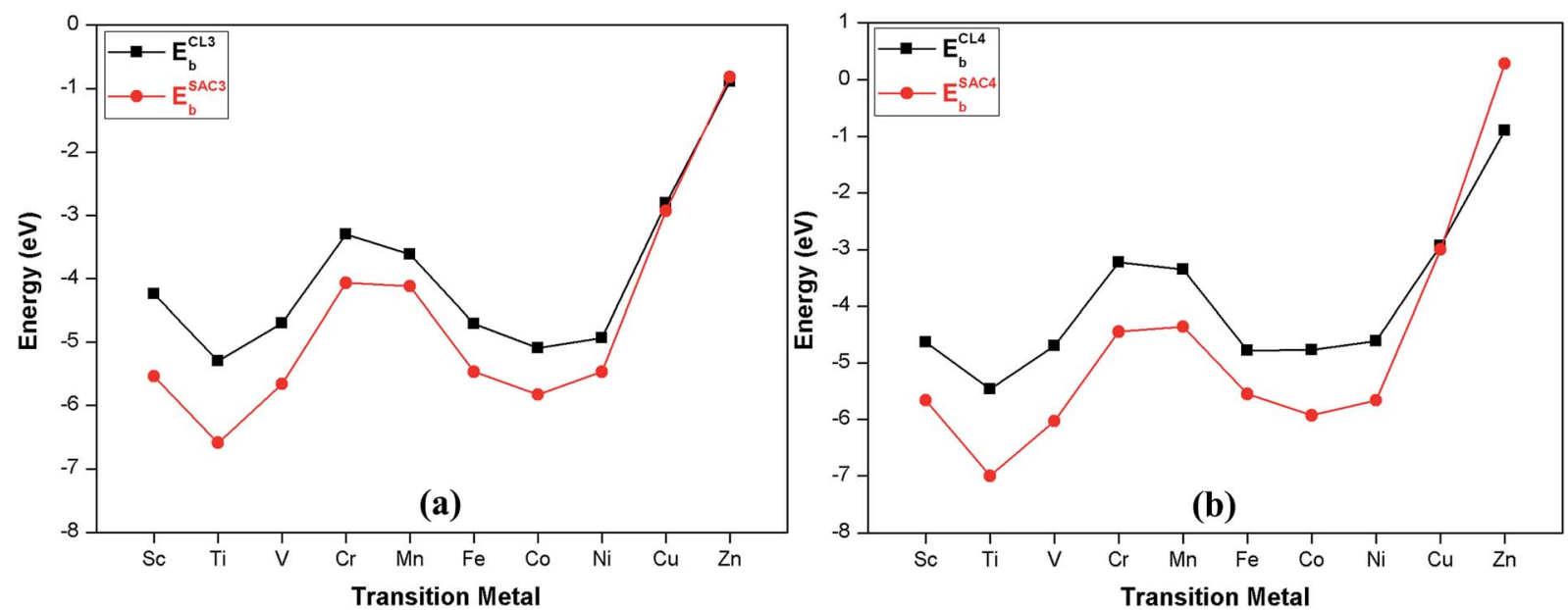

Fig. $2 E_{\mathrm{b}}^{\mathrm{SAC3}}$ and $E_{\mathrm{b}}^{\mathrm{SAC} 4}$ are the binding energies of embedded three and four metal atoms with the $\mathrm{B}_{\beta 12}$ monolayer. $E_{\mathrm{b}}^{\mathrm{CL} 3}$ and $E_{\mathrm{b}}^{\mathrm{CL} 4}$ are the binding energies of metal clusters (comprised of three and four metal atoms) with the $B_{\beta 12}$ monolayer. 


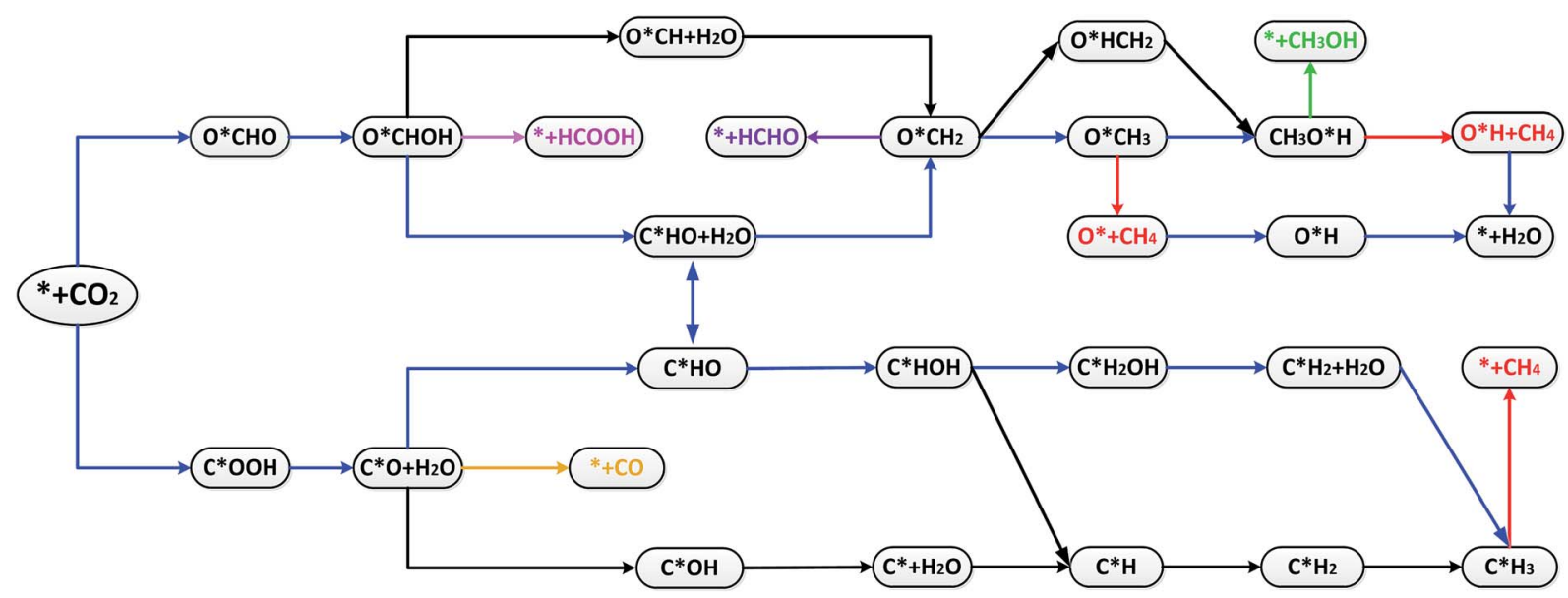

Scheme 1 Most likely reaction pathways for the electroreduction of $\mathrm{CO}_{2}$ on $\mathrm{TM}-\mathrm{B}_{\beta 12}$.

If the absolute value of the binding energy $\left(E_{\mathrm{b}}^{\mathrm{SAC} 1}\right)$ is larger than the absolute value of the cohesive energy $\left(E_{\mathrm{c}}\right)$ of the corresponding bulk metal, this means that the metal atom is more likely to bind with the $\mathrm{B}_{\beta 12}$ monolayer, thus indicating that the $\mathrm{TM}-\mathrm{B}_{\beta 12}$ monolayer has excellent stability. It can be seen from Table $\mathrm{S} 1 \uparrow$ that the absolute value of $E_{\mathrm{b}}^{\mathrm{SAC} 1}$ (except Sc and Ti) are smaller than the absolute value of $E_{\mathrm{c}}$. Considering the binding energies of the clusters of 3 and 4 metal atoms with $\mathrm{B}_{\beta 12}$ monolayer $\left(E_{\mathrm{b}}^{\mathrm{CL} 3}\right.$ and $\left.E_{\mathrm{b}}^{\mathrm{CL} 4}\right)$, the absolute values of $E_{\mathrm{b}}^{\mathrm{CL} 3}$ and $E_{\mathrm{b}}^{\mathrm{CL} 4}$ (except $\mathrm{Zn}$ ) are smaller than the absolute value of $E_{\mathrm{b}}^{\mathrm{SAC} 3}$ and $E_{\mathrm{b}}^{\mathrm{SAC} 4}$ of the corresponding 3 and 4 dispersed metal atoms with $\mathrm{B}_{\beta 12}$ monolayer (as shown from Fig. 2 and Table S2 $\dagger$ ), which indicates that the dispersed metal atoms have stronger binding ability to the $B_{\beta 12}$ monolayer than the metal clusters (except for $\mathrm{Zn}$ ). Therefore, the metal atoms are more likely to bind to the $\mathrm{B}_{\beta 12}$ monolayer. Furthermore, the binding energy for individual atoms is relatively large and ranges from 3 to $6 \mathrm{eV}$ (other than $\mathrm{Zn}$ ) so the $\mathrm{TM}-\mathrm{B}_{\beta 12}$ monolayers (other than $\mathrm{Zn}$ ) have strong stability.

\subsection{First hydrogenation: selectivity for CRR vs. HER}

Since $\mathrm{CO}_{2}$ reduction occurs in aqueous solution, the protonelectron pair $\left(\mathrm{H}^{+}+\mathrm{e}^{-}\right)$required for CRR is mainly derived from water. The metal atom directly accepts a proton-electron pair to produce $\mathrm{H}^{*}\left(*+\mathrm{H}^{+}+\mathrm{e}^{-} \rightarrow \mathrm{H}^{*}\right)$. If the reaction continues, $\mathrm{H}_{2}$ will be desorbed from the surface of the catalyst. This is called the hydrogen evolution reaction (HER). HER as a side reaction of CRR could potentially reduce the efficiency of the catalysts, so the selectivity of these new materials for CRR versus HER must be considered. The first step of the protonation of CRR is based on the path $\mathrm{CO}_{2}+\mathrm{H}^{+}+\mathrm{e}^{-} \rightarrow \mathrm{C}^{*} \mathrm{OOH}$ or $\mathrm{O}^{*} \mathrm{CHO}$ to produce two intermediates, $\mathrm{C}^{*} \mathrm{OOH}$ or $\mathrm{O}^{*} \mathrm{CHO}$. The Gibbs free energy change for the first hydrogenation step can be used to determine whether the monolayer binding with $\mathrm{C}^{*} \mathrm{OOH}$ or $\mathrm{O}^{*} \mathrm{CHO}$ (or with $\mathrm{H}^{*}$ ) is stable. The more negative the Gibbs free energy change, the more stable the binding. Because the metal active sites of the $\mathrm{TM}-\mathrm{B}_{\beta 12}$ monolayer surface are limited, if the monolayer binds to $\mathrm{C}^{*} \mathrm{OOH}$ or $\mathrm{O}^{*} \mathrm{CHO}$ stably, the active site will be occupied, which will make $\mathrm{H}^{*}$ difficult to form. Thus, the catalyst has a good CRR selectivity. It can be seen from Fig. 3, that for the monolayers considered, all metals are below the dotted line, indicating strong CRR selectivity (see Table S2 $\dagger$ ).

\subsection{Reaction pathway analysis of CRR}

The optimal reaction paths and catalytic products of these materials during CRR will now be discussed. Scheme 1 shows the most favorable reaction pathways of CRR. Fig. 4 shows the important intermediates for the whole $8 \mathrm{e}^{-}$reaction process. Each step in the protonation of CRR has two different $\mathrm{H}$-adding positions (onto the $\mathrm{C}$ atom, or onto the $\mathrm{O}$ atom). Therefore $\mathrm{CRR}$ has many possible reaction paths. In addition, it is possible for $\mathrm{CO}_{2}$ to produce different reduction products by accepting different numbers of proton-electron pairs. The most likely reaction paths and reaction products for CRR on these materials, will be determined by the reaction Gibbs free energy change, the overpotential, the adsorption energy, and other factors.

The intermediates $\mathrm{C} * \mathrm{OOH}$ and $\mathrm{O} * \mathrm{CHO}$ can continue to protonate and then follow the path $\mathrm{C}^{*} \mathrm{OOH}+\mathrm{H}^{+}+\mathrm{e}^{-} \rightarrow \mathrm{C}^{*} \mathrm{O}$ and $\mathrm{O}^{*} \mathrm{CHO}+\mathrm{H}^{+}+\mathrm{e}^{-} \rightarrow \mathrm{O}^{*} \mathrm{CHOH}$ to produce $\mathrm{C}^{*} \mathrm{O}$ and $\mathrm{O}^{*} \mathrm{CHOH}$, respectively. If the adsorption energy of $\mathrm{CO}$ and $\mathrm{HCOOH}$ are small enough, they will become products and desorb from the surface $\left(\mathrm{C}^{*} \mathrm{O}+\mathrm{H}_{2} \mathrm{O} \rightarrow *+\mathrm{CO}\right.$ or $\mathrm{O} * \mathrm{CHOH} \rightarrow$ $*+\mathrm{HCOOH}$ ). Conversely, if the adsorption energy of $\mathrm{CO}$ and $\mathrm{HCOOH}$ are large, it makes them difficult to desorb, but then they can continue to be reduced as reaction intermediates. Table $\mathrm{S} 3 \uparrow$ shows that the adsorption energy of $\mathrm{Sc}-\mathrm{B}_{\beta 12}$ for $\mathrm{CO}$ and $\mathrm{HCOOH}$ are -0.40 and $-1.02 \mathrm{eV}$, respectively, which indicates that the adsorption energy of $\mathrm{CO}$ is smaller than that of $\mathrm{HCOOH}$, and it is therefore easier to desorb from the surface to become a reduction product. Therefore, the reduction product of CRR for Sc is mainly CO (as shown in Fig. 5a). In addition, for Ti through $\mathrm{Zn}$, the adsorption energy 


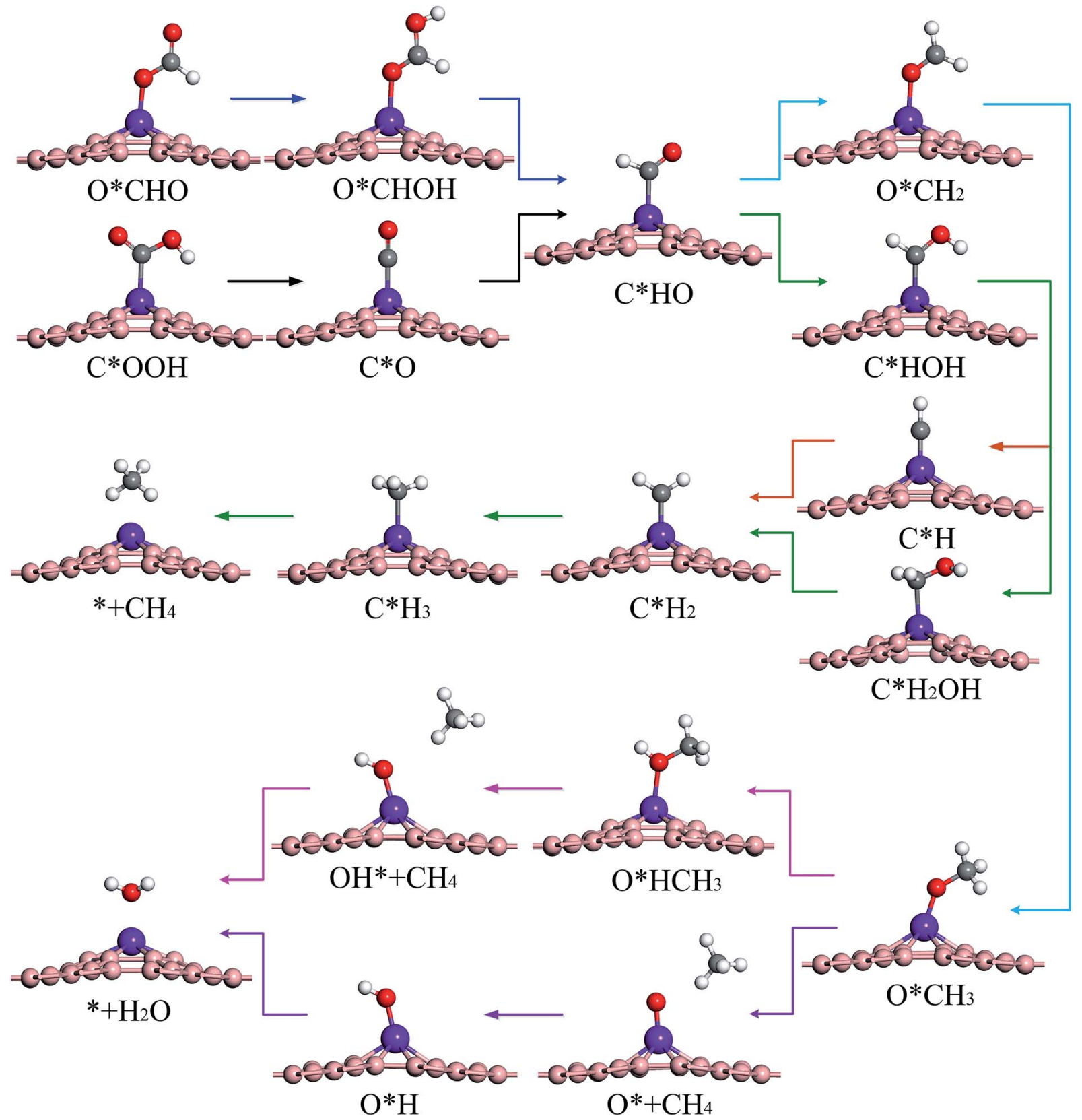

Fig. 4 Optimized geometric structures of key reaction intermediates of CRR.

of $\mathrm{CO}$ and $\mathrm{HCOOH}$ are in the range of -0.92 to $-2.24 \mathrm{eV}$ and -0.78 to $-1.35 \mathrm{eV}$, respectively, indicating that it is difficult to get $2 \mathrm{e}^{-}$products from these materials, for both $\mathrm{CO}$ and $\mathrm{HCOOH}$. Therefore, $\mathrm{CO}$ and $\mathrm{HCOOH}$ can continue to participate in the reaction as reaction intermediates.

$\mathrm{CO}$ and $\mathrm{HCOOH}$ can continue to be protonated to produce three intermediates: $\mathrm{C}^{*} \mathrm{HO}, \mathrm{C}^{*} \mathrm{HO}$ and $\mathrm{O} * \mathrm{CH}$. Compared to $\mathrm{C}^{*} \mathrm{OH}$ and $\mathrm{O}^{*} \mathrm{CH}$, the Gibbs free energy change for $\mathrm{C}^{*} \mathrm{HO}$ is smaller, so it is easier to form $\mathrm{C}^{*} \mathrm{HO}$. It can be seen from Fig. $5 \mathrm{~b}$, c, d, g, i and $\mathrm{j}$ that $\mathrm{Ti}, \mathrm{V}, \mathrm{Cr}, \mathrm{Co}, \mathrm{Cu}$ and $\mathrm{Zn}$ are more likely to follow the path $\mathrm{C}^{*} \mathrm{OOH} \rightarrow \mathrm{C}^{*} \mathrm{O} \rightarrow \mathrm{C}^{*} \mathrm{HO}$ to produce $\mathrm{C}^{*} \mathrm{HO}$. On the other hand $\mathrm{Mn}, \mathrm{Fe}, \mathrm{Ni}$ are more likely to produce $\mathrm{C}^{*} \mathrm{HO}$ according to the path $\mathrm{O}^{*} \mathrm{CHO} \rightarrow \mathrm{O}^{*} \mathrm{CHOH} \rightarrow \mathrm{C}^{*} \mathrm{HO}+\mathrm{H}_{2} \mathrm{O}$ (as shown in Fig. 5e, $\mathrm{f}$ and $\mathrm{h}$ ). Scheme 1 shows that $\mathrm{C}^{*} \mathrm{HO}$ can continue to hydrogenate to give the products $\mathrm{HCHO}\left(4 \mathrm{e}^{-}\right)$, $\mathrm{CH}_{3} \mathrm{OH}\left(6 \mathrm{e}^{-}\right)$and $\mathrm{CH}_{4}\left(8 \mathrm{e}^{-}\right)$. Table $\mathrm{S} 3 \dagger$ shows the adsorption energies of $\mathrm{HCHO}$ and $\mathrm{CH}_{3} \mathrm{OH}$ for Ti through $\mathrm{Zn}$ are in the range of -0.73 to $-2.24 \mathrm{eV}$ and -0.78 to $-1.35 \mathrm{eV}$, respectively. The adsorption energy of $\mathrm{CH}_{4}$ is in the range of -0.12 to $-0.52 \mathrm{eV}$, which indicates that the products of these 9 catalysts from Ti to $\mathrm{Zn}$ are mostly $\mathrm{CH}_{4}$. As can be seen from Scheme 1, creating $\mathrm{CH}_{4}$ from the intermediate $\mathrm{C}^{*} \mathrm{HO}$ has four main pathways: 

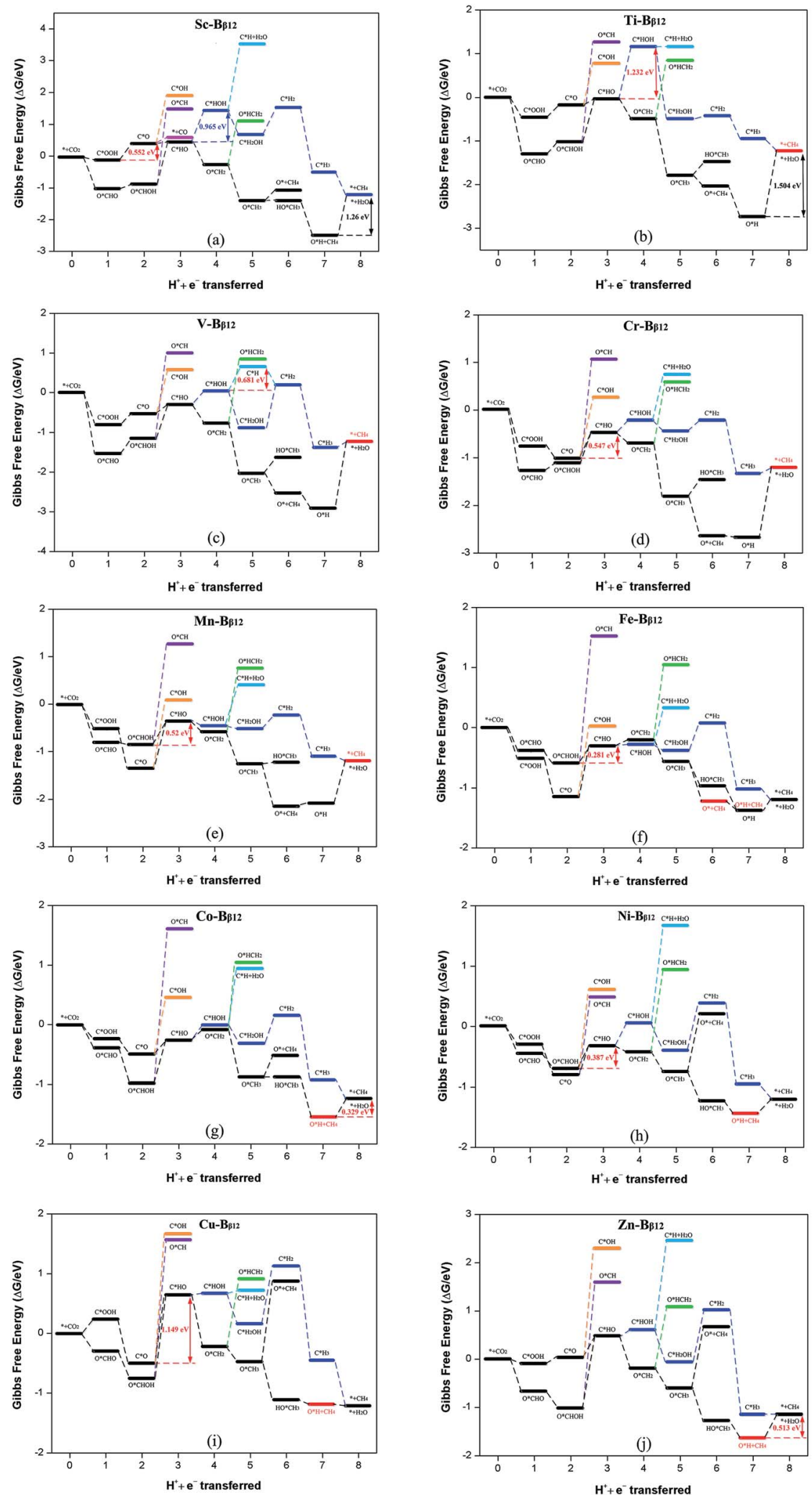

Fig. 5 Gibbs free energy profiles for $C R R$ along the most favorable pathways for (a) $S c-B_{\beta 12}$, (b) Ti- $B_{\beta 12}$, (c) $V-B_{\beta 12}$, (d) $C r-B_{\beta 12,}$, (e) $M n-B_{\beta 12}$, (f) $\mathrm{Fe}-\mathrm{B}_{\beta 12}$, (g) $\mathrm{Co}-\mathrm{B}_{\beta 12}$, (h) $\mathrm{Ni}-\mathrm{B}_{\beta 12}$, (i) $\mathrm{Cu}-\mathrm{B}_{\beta 12}$ and (j) $\mathrm{Zn}-\mathrm{B}_{\beta 12}$ at zero potential. $A \mathrm{CO}_{2}$ molecule in the gas phase with a clean catalyst surface sets the free energy zero point. 
Table 2 Calculated potential determining steps (PDS), limiting potentials $\left(U_{L} / V\right)$, equilibrium potential of different reduction products $\left(U_{\text {eq }} / \mathrm{V}, v s\right.$. SHE, $\left.\mathrm{pH}=0\right)$ and overpotentials $(\eta / \mathrm{V})$ for the CRR

\begin{tabular}{llccc}
\hline $\mathrm{TM}^{-} \mathrm{B}_{\beta 12}$ & PDS & $U_{\mathrm{L}}$ & $U_{\text {eq }}$ (product) & $\eta$ \\
\hline $\mathrm{Sc}-\mathrm{B}_{\beta 12}$ & $\mathrm{C}^{*} \mathrm{OOH} \rightarrow \mathrm{C}^{*} \mathrm{O}+\mathrm{H}_{2} \mathrm{O}$ & -0.552 & $-0.106(\mathrm{CO})$ & 0.446 \\
$\mathrm{Ti}^{-} \mathrm{B}_{\beta 12}$ & $\mathrm{C}^{*} \mathrm{HO} \rightarrow \mathrm{C}^{*} \mathrm{HOH}$ & -1.232 & $0.169\left(\mathrm{CH}_{4}\right)$ & 1.401 \\
$\mathrm{~V}^{-} \mathrm{B}_{\beta 12}$ & $\mathrm{C}^{*} \mathrm{HOH} \rightarrow \mathrm{C} \mathrm{C}^{*}+\mathrm{H}_{2} \mathrm{O}$ & -0.681 & $0.169\left(\mathrm{CH}_{4}\right)$ & 0.850 \\
$\mathrm{Cr}-\mathrm{B}_{\beta 12}$ & $\mathrm{C}^{*} \mathrm{O} \rightarrow \mathrm{C}^{*} \mathrm{HO}$ & -0.547 & $0.169\left(\mathrm{CH}_{4}\right)$ & 0.716 \\
$\mathrm{Mn}-\mathrm{B}_{\beta 12}$ & $\mathrm{O}^{*} \mathrm{CHOH} \rightarrow \mathrm{C} \mathrm{HO}+\mathrm{H}_{2} \mathrm{O}$ & -0.520 & $0.169\left(\mathrm{CH}_{4}\right)$ & 0.689 \\
$\mathrm{Fe}-\mathrm{B}_{\beta 12}$ & $\mathrm{O}^{*} \mathrm{CHOH} \rightarrow \mathrm{C}^{*} \mathrm{HO}+\mathrm{H}_{2} \mathrm{O}$ & -0.281 & $0.169\left(\mathrm{CH}_{4}\right)$ & 0.450 \\
$\mathrm{Co}-\mathrm{B}_{\beta 12}$ & $\mathrm{O}^{*} \mathrm{H} \rightarrow *+\mathrm{H}_{2} \mathrm{O}$ & -0.329 & $0.169\left(\mathrm{CH}_{4}\right)$ & 0.498 \\
$\mathrm{Ni}-\mathrm{B}_{\beta 12}$ & $\mathrm{O}^{*} \mathrm{CHOH} \rightarrow \mathrm{C} \mathrm{HO}+\mathrm{H}_{2} \mathrm{O}$ & -0.387 & $0.169\left(\mathrm{CH}_{4}\right)$ & 0.556 \\
$\mathrm{Cu}-\mathrm{B}_{\beta 12}$ & $\mathrm{C}^{*} \mathrm{O} \rightarrow \mathrm{C}^{*} \mathrm{HO}$ & -1.149 & $0.169\left(\mathrm{CH}_{4}\right)$ & 1.318 \\
$\mathrm{Zn}-\mathrm{B}_{\beta 12}$ & $\mathrm{O}^{*} \mathrm{H} \rightarrow *+\mathrm{H}_{2} \mathrm{O}$ & -0.513 & $0.169\left(\mathrm{CH}_{4}\right)$ & 0.682
\end{tabular}

$$
\begin{aligned}
& \text { (1) } \begin{array}{rl}
\mathrm{C} * & \mathrm{HO} \rightarrow \\
\rightarrow & \mathrm{C} * \mathrm{HOH} \rightarrow \mathrm{C}^{*} \mathrm{H}+\mathrm{H}_{2} \mathrm{O} \rightarrow \mathrm{C}^{*} \mathrm{H}_{2} \rightarrow \mathrm{C}^{*} \mathrm{H}_{3} \\
& \rightarrow \mathrm{CH}_{4}
\end{array} \\
& \text { (2) } \mathrm{C}^{*} \mathrm{HO} \rightarrow \mathrm{C}^{*} \mathrm{HOH} \rightarrow \mathrm{C}^{*} \mathrm{H}_{2} \mathrm{OH} \rightarrow \mathrm{C}^{*} \mathrm{H}_{2}+\mathrm{H}_{2} \mathrm{O} \\
& \rightarrow \mathrm{C}^{*} \mathrm{H}_{3} \rightarrow *+\mathrm{CH}_{4} \\
& \text { (3) } \mathrm{C}^{*} \mathrm{HO} \rightarrow \mathrm{O}^{*} \mathrm{CH}_{2} \rightarrow \mathrm{O}^{*} \mathrm{CH}_{3} \rightarrow \mathrm{O}^{*}+\mathrm{CH}_{4} \rightarrow \mathrm{O} * \mathrm{H} \\
& \rightarrow *+\mathrm{H}_{2} \mathrm{O} \\
& \text { (4) } \mathrm{C} * \mathrm{HO} \rightarrow \mathrm{O}^{*} \mathrm{CH}_{2} \rightarrow \mathrm{O}^{*} \mathrm{HCH}_{2} \rightarrow \mathrm{O} * \mathrm{HCH}_{3} \\
& \rightarrow \mathrm{O} * \mathrm{H}+\mathrm{CH}_{4} \rightarrow *+\mathrm{H}_{2} \mathrm{O}
\end{aligned}
$$

According to the principle that the lower the energy barrier, the more likely the reaction, $\mathrm{V}$ will primarily follow path (1), Ti, $\mathrm{Cr}$ and Mn will primarily follow path (2), Fe will primarily follow path (3), and $\mathrm{Co}, \mathrm{Ni}, \mathrm{Cu}$ and $\mathrm{Zn}$ will primarily follow path (4).

The overpotential determines how efficient these catalysts will be in practical application. The smaller the overpotential, the smaller the applied voltage required for CRR, and the easier the reaction. Therefore, in order to have a strong catalytic effect, these new materials must have a small overpotential. Table 2 summarizes the potential determining steps, limit potential, and overpotential of these materials. The results show that the primary catalytic product of $\mathrm{Sc}$ is $\mathrm{CO}$ and its corresponding overpotential is $0.45 \mathrm{~V}$. The remaining 9 materials primarily produce $\mathrm{CH}_{4}$, with overpotentials from 0.45 to $1.40 \mathrm{~V}$. Only the overpotentials for $\mathrm{Ti}$ and $\mathrm{Cu}$ are greater than $1 \mathrm{~V}$, while the other overpotentials are all less than $0.85 \mathrm{~V}$. This is comparable to or even lower than the $1 \mathrm{~V}$ overpotential of CRR by polycrystalline copper that has been studied extensively in the past. ${ }^{27-29}$ The performance of the new $\mathrm{TM}-\mathrm{B}_{\beta 12}$ monolayers is comparable to that of $\mathrm{Cu}$ atomic chain decorated boron nanosheets. ${ }^{30} \mathrm{In}$ addition, the overpotential of the CRR catalyst designed in this paper is comparable to or even smaller than that of other promising experimentally known catalysts in the literature. Examples include: monodisperse Au nanoparticles $(\eta=0.26$ $\mathrm{V}),{ }^{31}$ the modified $\mathrm{Cu}$ electrode from the reduction of thick $\mathrm{Cu}_{2} \mathrm{O}$ films $(\eta=0.50 \mathrm{~V}),{ }^{32} \mathrm{~N}$-doped carbon nanotubes $(\eta=$ $0.54 \mathrm{~V}),^{33}$ and nanoporous $\mathrm{Ag}(\eta<0.50 \mathrm{~V}) .^{34}$ Therefore, we predict that the $\mathrm{TM}-\mathrm{B}_{\beta 12}$ monolayer will have excellent catalytic activity for CRR.

\subsection{Electronic structure analysis}

For these new catalysts, the interaction between the transition metal atoms and the $\beta$-type B monolayer will greatly affect the CRR catalytic performance. From the PDOS diagram of Fig. S1, $\dagger$ it can be seen that the $3 \mathrm{~d}$ orbitals of the metal atoms in the monolayer overlap with the $2 p$ orbitals of the B atoms, which indicates that there is a strong interaction between the metal atoms and the B monolayer. For the 9 monolayers with primary reduction product $\mathrm{CH}_{4}$, the $3 \mathrm{~d}$ orbitals of $\mathrm{Cr}, \mathrm{Mn}, \mathrm{Fe}$, Co and $\mathrm{Ni}$ overlap better with the B-2p orbitals. This indicates that their interaction with the B monolayer is stronger than for the other metals. Moreover, it can be seen from Table 2 that the overpotentials are also smaller than for the other metals (except for $\mathrm{Zn}$ ). Thus, we can conclude that the stronger the interaction of the metal atoms with the $\mathrm{B}$ monolayer, the lower the overpotential for catalytic $\mathrm{CO}_{2}$ reduction. In addition, it can be seen from Table 2 that the overpotentials of $\mathrm{Fe}$, Co and Ni are relatively close and lower than for the other metals. Table 1 shows that $\mathrm{Fe}$, Co and Ni carry much less charge than the other metals. We see that the amount of electrons transferred when the metal atom interacts with the B monolayer correlates with the catalytic ability of these materials.

In addition, the strength of the interaction between the reaction intermediates and the monolayers has a great influence on whether CRR can proceed smoothly. If the monolayer binds the intermediates too strongly, the catalyst can lose its activity and the so-called poisoning phenomenon can appear. Conversely, if the binding is too weak, the intermediate will easily fall off the surface of the catalyst, which will make the reduction reaction not likely to continue. Therefore, it is necessary to have a suitable adsorption energy for the intermediates on the catalysts. In addition, the interaction between the reaction intermediates and the TM$B_{\beta 12}$ monolayers have a great influence on the magnitude of the overpotential of CRR. If the interaction is too strong, the Gibbs free energy of the protonation reaction at the potential determining step will increase, and the energy barrier of the reaction will also increase. The higher the energy barrier of the potential determining step, the bigger the overpotential of the reaction. According to the organometallic catalyst metal coordination theory, the intermediate and $\mathrm{TM}-\mathrm{B}_{\beta 12}$ mainly interact through the $\sigma$-bond and the $\pi$-bond. Fig. 6 show the PDOS diagrams of the reaction intermediates in the potential determining step of different $\mathrm{TM}-\mathrm{B}_{\beta 12}$ monolayers catalyzed $\mathrm{CO}_{2}$ reduction reactions. The $3 \mathrm{~d}$ orbitals of the metal atoms in the $\mathrm{TM}-\mathrm{B}_{\beta}$ monolayers and the carbon or oxygen in the intermediates overlap with different degrees. For $\mathrm{Ti}, \mathrm{V}$, and $\mathrm{Cu}$ (Fig. 6b, c and i), the metal atom states overlap with the $2 \mathrm{p}$ orbitals of carbon or oxygen in the intermediates more than the other metals. This indicates that $\mathrm{Ti}, \mathrm{V}$, and $\mathrm{Cu}$ monolayers interact more strongly with the intermediates of the potential determining step. Table 2 also shows that their corresponding overpotentials are higher than the other metals. This can explain that why $\mathrm{Ti}, \mathrm{V}$, and $\mathrm{Cu}$ monolayers have relatively high energy barriers for CRR. 

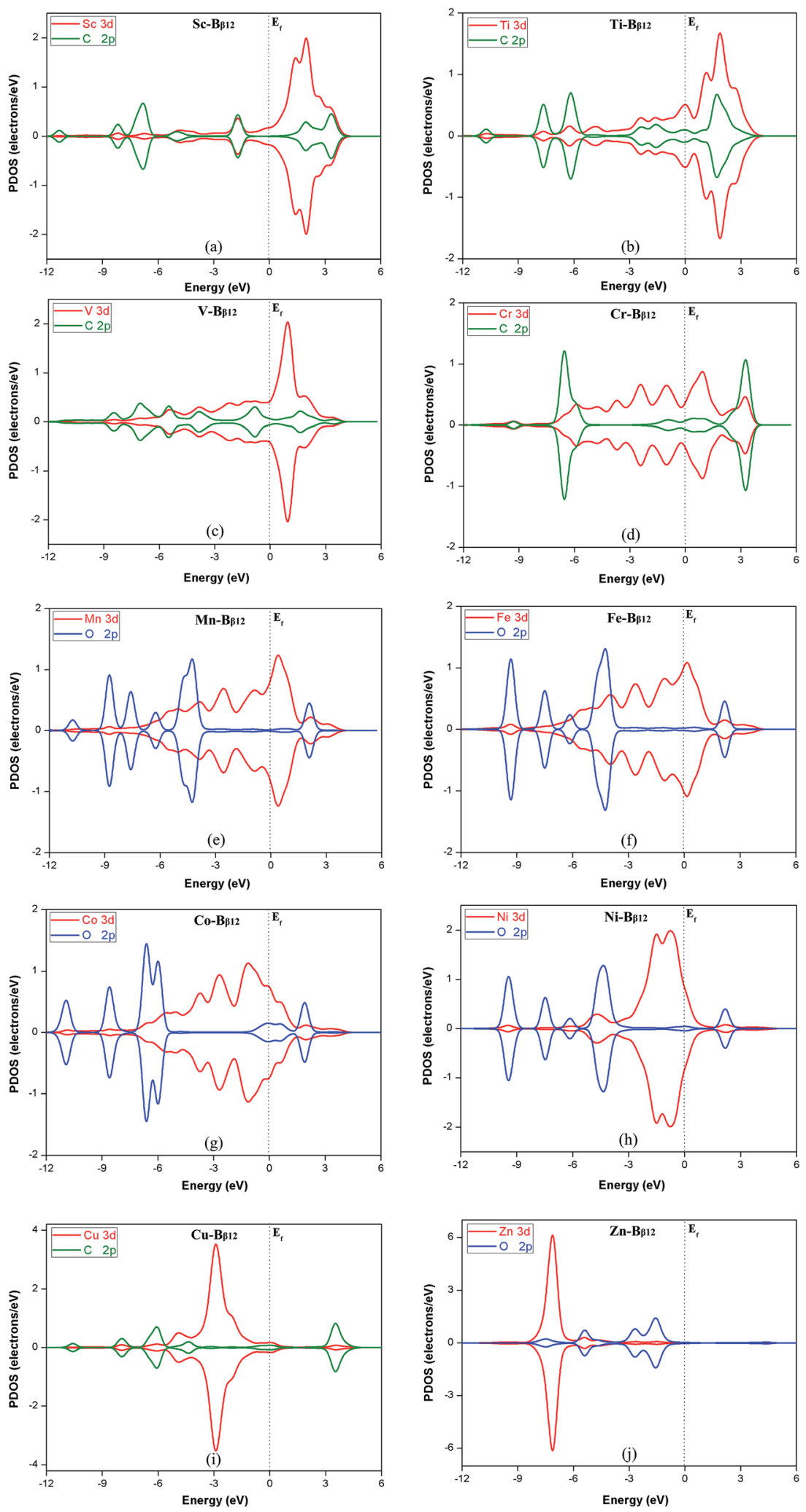

Fig. 6 Projected partial density of states (PDOS) of (a) $\mathrm{C} * \mathrm{OOH}$ adsorbed on $\mathrm{Sc}-\mathrm{B}_{\beta 12}$, (b) $\mathrm{C} * \mathrm{HO}$ on $\mathrm{Ti}-\mathrm{B}_{\beta 12}$, (c) $\mathrm{C} * \mathrm{HOH}$ on $\mathrm{V}-\mathrm{B}_{\beta 12}$, (d) $\mathrm{C} * \mathrm{O}$ on $\mathrm{Cr}-$ $\mathrm{B}_{\beta 12}$, (e) $\mathrm{O} * \mathrm{CHOH}$ on $\mathrm{Mn}_{-} \mathrm{B}_{\beta 12}$, (f) $\mathrm{O} * \mathrm{CHOH}$ on $\mathrm{Fe}-\mathrm{B}_{\beta 12}$, (g) $\mathrm{O} * \mathrm{H}$ on $\mathrm{Co}-\mathrm{B}_{\beta 12}$, (h) $\mathrm{O} * \mathrm{CHOH}$ on $\mathrm{Ni}-\mathrm{B}_{\beta 12}$, (i) $\mathrm{C} * \mathrm{O}$ on $\mathrm{Cu}-\mathrm{B}_{\beta 12}$ (j) $\mathrm{O} * \mathrm{H}$ on $\mathrm{Zn}-\mathrm{B}_{\beta 12}$. The dotted line denotes the Fermi level. The red, blue and green lines represent the $3 \mathrm{~d}$ orbital of the metal atom, and the $2 \mathrm{p}$ orbital of the oxygen and carbon atom, respectively. 


\section{Conclusions}

In summary, this paper used density functional theory to study the catalytic properties of $\mathrm{TM}-\mathrm{B}_{\beta 12}$ monolayers. The results show that the metal atoms can be stably combined with the $\beta$ type boron monolayer. The catalysts show excellent CRR selectivity. The primary reduction product for Sc is $\mathrm{CO}$, with $0.45 \mathrm{~V}$ overpotential. The primary product for the other metals (Ti-Zn) is $\mathrm{CH}_{4}$ and the overpotentials are all lower than $0.90 \mathrm{~V}$ (except for $\mathrm{Ti}$ and $\mathrm{Cu}$ which are greater than $1.30 \mathrm{~V}$ ). Remarkably, the overpotential for Fe is only $0.45 \mathrm{~V}$. Therefore, these new TM$\mathrm{B}_{\beta 12}$ materials are predicted to be remarkable CRR catalysts. Our results also provide theoretical support for future experimental study of these materials.

\section{Conflicts of interest}

There are no conflicts of interest to declare

\section{Acknowledgements}

J.-H. L. and L.-M. Y. gratefully acknowledge support from the National Natural Science Foundation of China (21673087 and 21873032), Startup Fund (2006013118 and 3004013105) from Huazhong University of Science and Technology, and the Fundamental Research Funds for the Central Universities (2019kfyRCPY116). The authors thank the Minnesota Supercomputing Institute (MSI) at the University of Minnesota for supercomputing resources.

\section{References}

1 S. J. Davis, K. Caldeira and H. D. Matthews, Future $\mathrm{CO}_{2}$ Emissions and Climate Change from Existing Energy Infrastructure, Science, 2010, 329, 1330-1333.

2 W. Wang, S. Wang, X. Ma and J. Gong, Recent advances in catalytic hydrogenation of carbon dioxide, Chem. Soc. Rev., 2011, 40, 3703-3727.

3 G. Peng, S. J. Sibener, G. C. Schatz, S. T. Ceyer and M. Mavrikakis, $\mathrm{CO}_{2}$ Hydrogenation to Formic Acid on Ni(111), J. Phys. Chem. C, 2012, 116, 3001-3006.

4 S. N. Habisreutinger, L. Schmidt-Mende and J. K. Stolarczyk, Photocatalytic Reduction of $\mathrm{CO}_{2}$ on $\mathrm{TiO}_{2}$ and Other Semiconductors, Angew. Chem., Int. Ed., 2013, 52, 7372-7408.

5 J. Shi, Y. Jiang, Z. Jiang, X. Wang, X. Wang, S. Zhang, P. Han and C. Yang, Enzymatic conversion of carbon dioxide, Chem. Soc. Rev., 2015, 44, 5981-6000.

6 J. Klankermayer, S. Wesselbaum, K. Beydoun and W. Leitner, Selective Catalytic Synthesis Using the Combination of Carbon Dioxide and Hydrogen: Catalytic Chess at the Interface of Energy and Chemistry, Angew. Chem., Int. Ed., 2016, 55, 7296-7343.

7 M. Gattrell, N. Gupta and A. Co, Electrochemical reduction of $\mathrm{CO}_{2}$ to hydrocarbons to store renewable electrical energy and upgrade biogas, Energy Convers. Manage., 2007, 48, 12551265.
8 A. A. Peterson and J. K. Nørskov, Activity Descriptors for $\mathrm{CO}_{2}$ Electroreduction to Methane on Transition-Metal Catalysts, J. Phys. Chem. Lett., 2012, 3, 251-258.

9 J. Qiao, Y. Liu, F. Hong and J. Zhang, A review of catalysts for the electroreduction of carbon dioxide to produce lowcarbon fuels, Chem. Soc. Rev., 2014, 43, 631-675.

10 Y. Li, S. H. Chan and Q. Sun, Heterogeneous catalytic conversion of $\mathrm{CO}_{2}$ : a comprehensive theoretical review, Nanoscale, 2015, 7, 8663-8683.

11 S. Back, M. S. Yeom and Y. Jung, Active Sites of Au and Ag Nanoparticle Catalysts for $\mathrm{CO}_{2}$ Electroreduction to CO, ACS Catal., 2015, 5, 5089-5096.

12 D. D. Zhu, J. L. Liu and S. Z. Qiao, Recent Advances in Inorganic Heterogeneous Electrocatalysts for Reduction of Carbon Dioxide, Adv. Mater., 2016, 28, 3423-3452.

13 Z. Sun, T. Ma, H. Tao, Q. Fan and B. Han, Fundamentals and Challenges of Electrochemical $\mathrm{CO}_{2}$ Reduction Using TwoDimensional Materials, Chem, 2017, 3, 560-587.

14 J.-H. Liu, L.-M. Yang and E. Ganz, Efficient and Selective Electroreduction of $\mathrm{CO}_{2}$ by Single-Atom Catalyst TwoDimensional TM-Pc Monolayers, ACS Sustainable Chem. Eng., 2018, 6, 15494-15502.

15 J.-H. Liu, L.-M. Yang and E. Ganz, Electrochemical reduction of $\mathrm{CO}_{2}$ by single atom catalyst TM-TCNQ monolayers, $J$. Mater. Chem. A, 2019, 7, 3805-3814.

16 J.-H. Liu, L.-M. Yang and E. Ganz, Electrocatalytic reduction of $\mathrm{CO}_{2}$ by two-dimensional transition metal porphyrin sheets, J. Mater. Chem. A, 2019, 7, 11944-11952.

17 J. Shang, Y. Ma, Y. Gu and L. Kou, Two dimensional boron nanosheets: synthesis, properties and applications, Phys. Chem. Chem. Phys., 2018, 20, 28964-28978.

18 W. Li, L. Kong, C. Chen, J. Gou, S. Sheng, W. Zhang, H. Li, L. Chen, P. Cheng and K. Wu, Experimental realization of honeycomb borophene, Sci. Bull., 2018, 63, 282-286.

19 B. Song, Y. Zhou, H.-M. Yang, J.-H. Liao, L.-M. Yang, X.-B. Yang and E. Ganz, Two-Dimensional Anti-Van't Hoff/Le Bel Array $\mathrm{AlB}_{6}$ with High Stability, Unique Motif, Triple Dirac Cones, and Superconductivity, J. Am. Chem. Soc., 2019, 141, 3630-3640.

20 B. Delley, From molecules to solids with the $\mathrm{DMol}^{3}$ approach, J. Chem. Phys., 2000, 113, 7756-7764.

21 J. P. Perdew, K. Burke and M. Ernzerhof, Generalized Gradient Approximation Made Simple, Phys. Rev. Lett., 1996, 77, 3865-3868.

22 B. Delley, An all-electron numerical method for solving the local density functional for polyatomic molecules, J. Chem. Phys., 1990, 92, 508-517.

23 S. Grimme, Semiempirical GGA-type density functional constructed with a long-range dispersion correction, $J$. Comput. Chem., 2006, 27, 1787-1799.

24 J. Rossmeisl, A. Logadottir and J. K. Nørskov, Electrolysis of water on (oxidized) metal surfaces, Chem. Phys., 2005, 319, 178-184.

25 J. K. Nørskov, J. Rossmeisl, A. Logadottir, L. Lindqvist, J. R. Kitchin, T. Bligaard and H. Jónsson, Origin of the Overpotential for Oxygen Reduction at a Fuel-Cell Cathode, J. Phys. Chem. B, 2004, 108, 17886-17892. 
26 F. L. Hirshfeld, Bonded-atom fragments for describing molecular charge densities, Theor. Chim. Acta, 1977, 44, 129-138.

27 A. A. Peterson, F. Abild-Pedersen, F. Studt, J. Rossmeisl and J. K. Nørskov, How copper catalyzes the electroreduction of carbon dioxide into hydrocarbon fuels, Energy Environ. Sci., 2010, 3, 1311-1315.

28 K. P. Kuhl, E. R. Cave, D. N. Abram and T. F. Jaramillo, New insights into the electrochemical reduction of carbon dioxide on metallic copper surfaces, Energy Environ. Sci., 2012, 5, 7050-7059.

29 C. Shi, K. Chan, J. S. Yoo and J. K. Nørskov, Barriers of Electrochemical $\mathrm{CO}_{2}$ Reduction on Transition Metals, Org. Process Res. Dev., 2016, 20, 1424-1430.

$30 \mathrm{H}$. Shen, Y. Li and Q. Sun, Cu atomic chains supported on $\beta$ borophene sheets for effective $\mathrm{CO}_{2}$ electroreduction, Nanoscale, 2018, 10, 11064-11071.
31 W. L. Zhu, R. Michalsky, O. Metin, H. F. Lv, S. J. Guo, C. J. Wright, X. L. Sun, A. A. Peterson and S. H. Sun, Monodisperse $\mathrm{Au}$ nanoparticles for selective electrocatalytic reduction of $\mathrm{CO}_{2}$ to CO, J. Am. Chem. Soc., 2013, 135, 16833-16836.

32 C. W. Li and M. W. Kanan, CO2 Reduction at low overpotential on $\mathrm{Cu}$ electrodes resulting from the reduction of thick $\mathrm{Cu}_{2} \mathrm{O}$ films, J. Am. Chem. Soc., 2012, 134, 7231-7234.

33 S. Zhang, P. Kang, S. Ubnoske, M. K. Brennaman, N. Song, R. L. House, J. T. Glass and T. J. Meyer, Polyethylenimineenhanced electrocatalytic reduction of $\mathrm{CO}_{2}$ to formate at nitrogen-doped carbon nanomaterials, J. Am. Chem. Soc., 2014, 136, 7845-7848.

34 Q. Lu, J. Rosen, Y. Zhou, G. S. Hutchings, Y. C. Kimmel, J. G. Chen and F. Jiao, A selective and efficient electrocatalyst for carbon dioxide reduction, Nat. Commun., 2014, 5, 3242. 